\section{Mysterious disappearance of female investigators}

SIR - The results of the first year's European Young Investigator (EURYI) awards are worrying. The awards provide 25 young scientists with up to $€ 1.25$ million to establish research teams in Europe. Only three of the 25 initial recipients were women, far below the percentage working in science at the targeted career stage. This was not because women didn't apply in sufficient numbers: nearly a quarter of the applicants were female. Rather, male applicants were twice as likely to succeed.

EURYI applications were first submitted to the relevant national research councils, who could nominate a specific number of candidates. This selection cut the proportion of women from one-quarter to one-fifth. Each national research council oversaw a drop in the number of selected women. In Spain, where nearly a third of the applicants were women, not one was nominated. The all-male Spanish list emerged with the highest success rate in the later European rounds, nearly three times the average. From 133 national nominees, European evaluation committees created a shortlist of 67 , causing the largest drop in the proportion of women: $9.9 \pm 0.5 \%$ of men applying made the European shortlist, but only $4.7 \pm 1.4 \%$ of women did.

The working paper Evaluation of the EURYI Awards Scheme by L. Langfeldt and K. E. Brofoss (NIFU STEP, Oslo, 2005), commissioned by the European Science Foundation (ESF), with access to a limited data set including assessments of candidates at the European evaluations and sample applications, recently concluded: "the main problem remains that the scheme ... attracts far fewer female applicants. The report also suggested that "female applicants had a somewhat higher tendency to be filtered out ${ }^{n}$ at the domestic level but that there was "no evidence of bias" at a European level.

However, the statistics are clear: the consistent attrition of women at each stage, and the large size of the sample, mean that women's lack of success cannot have occurred by fluke. The random chance probability of halving the female fraction from one end of the competition to the other is only $0.05 \%$.

The 'leaking pipe' phenomenon (in which a disproportionate number of women leave the sciences at each career stage) is often attributed to a complex array of external factors that cause women to drop out. In this case, we believe we are seeing a leaking pipe in the stages of a single competition. Does this mean more straightforward explanations for the career leakage may be possible?

Without a detailed knowledge of applications and judging criteria, it is impossible to nail down the underlying reasons for the inequality in the awards. We would like to replicate the groundbreaking analysis of Christine Wennerås and Agnes Wold ("Nepotism and sexism in peer review" Nature 387, 341-343; 1997) at the European level, but the ESF has so far been unwilling to release the necessary data to us.

We consider that this attrition demands further independent scrutiny to uncover the cause.

Darach Watson, Anja C. Andersen, Jens Hjorth Dark Cosmology Centre, Niels Bohr Institute, University of Copenhagen, Juliane Maries Vej 30, 2100 Copenhagen $\emptyset$, Denmark

\section{Rising temperatures are likely to reduce crop yields}

SIR — Your News story about the Royal Society meeting on climate change and food production ("Hikes in surface ozone could suffocate crops ${ }^{\text {}}$ Nature 435,$7 ; 2005$ ) noted that rising $\mathrm{CO}_{2}$ levels will generally benefit crop growth, as this stimulates photosynthesis in most crop plants. However, the links between climate change and food production are even more complex than your story suggests.

Rising temperatures could extend the geographical distribution and growing season of some agricultural crops, such as pasture grasses, by allowing the threshold temperature for the start of growth to be reached sooner. This assumes that water and nutrients are supplied at a level that permits pasture crops to benefit from a longer growing season.

But in general, and contrary to common perceptions, most crop physiologists expect global warming to reduce crop yields. This is because higher temperatures shorten the life cycle of most cereals, hastening senescence and reducing the length of the growing season. Other effects such as an increase in tropospheric ozone level can exacerbate crop senescence, as noted in your News story. The staple cereal crops can only tolerate narrow temperature ranges, which, if exceeded during the flowering phase, can damage fertile seed production and thus reduce yield.

Global warming would also be expected to increase the frequency of exposure to extreme temperatures and thus damage crop fertility.

So far, efforts to predict climate change effects on food production and quality have been fragmented. For major crops, except wheat and soybean, we lack the agronomicscale experiments needed to understand and robustly predict the direct effects of $\mathrm{CO}_{2}$ and ozone, and their interactions with temperature and water. With an extra three billion people to feed during the coming 40 to 50 years, closer cooperation among crop physiology, crop agronomy and climate science would be a positive outcome of the Royal Society meeting. John R. Porter

Department of Agricultural Sciences,

The Royal Veterinary and Agricultural University, Hoejbakkegaard Avenue, 2630 Taastrup, Denmark

\section{No royal road to protein structure determination}

SIR - Your News story "Protein structures hint at the shape of things to come" (Nature $435,547 ; 2005)$ projects an excessively optimistic view of structural genomics, which your readership might find misleading.

The claim that "structural genomics initiatives are ready to roll out protein structures in large numbers" should be treated with scepticism. An alternative view predicts that the number of protein structure determinations will peak and then decline, as the pool of easy targets (so-called lowhanging fruit') gets depleted.

Recent technological advances have considerably eased the transit through some of the bottlenecks of crystallographic analysis. However, the unique biochemical properties of individual proteins continue to present a formidable barrier to any automated procedure of structure determination. A better way to assess the outcome of high-throughput initiatives would be to consider their overall success rate, given as the ratio of structures solved to the number of targets attempted.

It is for the grant agencies to decide whether funding of structural genomics programmes constitutes a worthwhile investment. Perhaps the most serious point, though, is that the wider scientific community might come to consider all structural biology endeavours as straightforward. This is not the case, especially at the frontier of modern structural biology, where the crystallographic analysis of large macromolecular complexes still requires heroic efforts. In this respect, the image that accompanies your News story is of a protein that structural biologists would consider not particularly challenging, and that is simpler than the four protein structures reported elsewhere in the same issue, obtained through traditional structural-biology approaches.

When asked by King Ptolemy I about an easy way to learn geometry, the Greek mathematician Euclid famously replied that there was no royal road to geometry. Paraphrasing Eudid, we could affirm with equal confidence that there is no royal road to protein structure determination. Luca Pellegrini

Biochemistry Department, University of

Cambridge, 80 Tennis Court Road,

Cambridge CB2 1GA, UK 